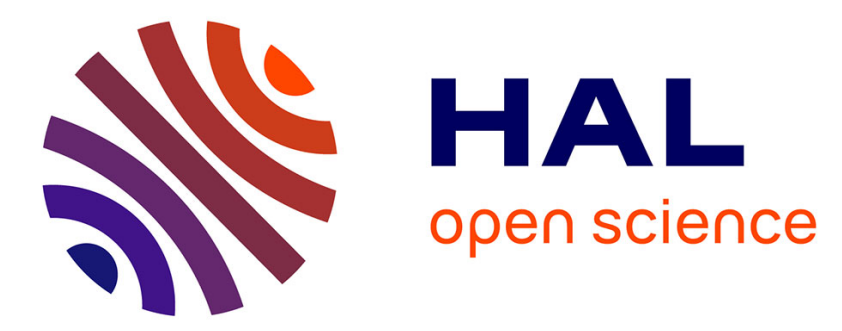

\title{
Experimental and computational performance of heat exchangers functioning in wet regime by using the film method
}

Cherif Bougriou, Rachid Bessaïh, André Bontemps

\section{To cite this version:}

Cherif Bougriou, Rachid Bessaïh, André Bontemps. Experimental and computational performance of heat exchangers functioning in wet regime by using the film method. International Communications in Heat and Mass Transfer, 2005, 32 (9), pp.1135-1142. 10.1016/j.icheatmasstransfer.2005.05.006 . hal-00184233

\section{HAL Id: hal-00184233 \\ https://hal.science/hal-00184233}

Submitted on 10 Feb 2020

HAL is a multi-disciplinary open access archive for the deposit and dissemination of scientific research documents, whether they are published or not. The documents may come from teaching and research institutions in France or abroad, or from public or private research centers.
L'archive ouverte pluridisciplinaire HAL, est destinée au dépôt et à la diffusion de documents scientifiques de niveau recherche, publiés ou non, émanant des établissements d'enseignement et de recherche français ou étrangers, des laboratoires publics ou privés. 


\title{
Experimental and computational performances of heat exchangers functioning in wet regime by using the film method
}

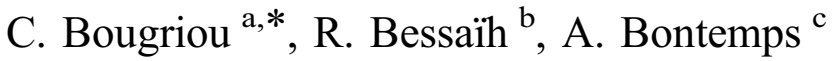 \\ ${ }^{a}$ LESEI, Département de Mécanique, Université de Batna, rue A. Boukhlouf, 05000 Batna, Algeria \\ ${ }^{\mathrm{b}}$ LEAP, Département de Génie Mécanique, Université Mentouri-Constantine, Route d'Ain El. Bey, 25000 Constantine, Algeria \\ c LEGI-GRETh, Universite' Joseph Fourier, 17 rue des Martyrs 38054 Grenoble Cedex 9, France
}

In this paper, we present a method of calculation by partial or total condensation of the water vapour contained in the humid air, over the smooth or finned tubes-heat recuperators. This study presents an implementation of the film method in a computer code developed here. The mathematical model used is validated by our experimental approach, using tubes bundles in staggered and aligned arrangements. The temperature of the humid air varies between $100{ }^{\circ} \mathrm{C}$ and $350{ }^{\circ} \mathrm{C}$. The determination of the fin portion, which functions in wet regime was carried out by the calculation of temperature field over a circular fin. The heat transfer coefficient by convection around the fin is supposed to be constant. The computer code predicts the heat flux exchanged in a range of $20 \%$ and $5 \%$, in wet and dry regime, respectively. The apparent heat transfer coefficient by condensation can exceed 10 times the value of the heat transfer coefficient.

Keywords: Heat exchangers; Finned tubes; Film method; Condensation; Non-condensable gas; Experimental; Computational

\section{Introduction}

Fin-and-tube heat exchangers are employed in a wide variety of engineering applications like airconditioning apparatus, process gas heaters, and coolers. The problem considered in this study concerns the finned-tube-heat exchangers calculation in the case of condensation of a vapour, in the presence of

\footnotetext{
* Corresponding author.

E-mail address: cherif_bougriou@hotmail.com (C. Bougriou).
} 
incondensable gases. This case is encountered during the heat evacuated by the dryers or boilers chimneys, and/or by vapour condensation contained in the ambient air, on the heat exchangers used for air-conditioning, etc. In this case, the saturation temperature varies along the heat exchanger. In addition, the vapour condensation in the presence of incondensable gases can start, although, that the average temperature of the mixture is higher than the saturation temperature. This, of course, is due to the low partial pressure of the vapour in the film: region situated between the condensation film and gas phase. This problem is, unfortunately, worsened in presence of fins posed on the tubes, because most of the fin surface works in dry regime during the vapour condensation. This is due to the temperature gradient on the fin: the temperature of the fin is higher than that of the outer wall tube. The bad estimate of the fin portion which works in wet regime influences directly on the latent heat flux calculation.

Many researchers have done a large number of studies. Ay et al. [1] determined experimentally the local heat transfer of plate finned-tube heat exchangers by infrared thermography. The results demonstrate that the averaged heat transfer coefficient of staggered configuration is $14-32 \%$ higher than that of in-lined configuration. Condensation heat transfer in a vertical tube has been investigated analytically by Pan [2], by considering the vapour flow and mass transfer. The results show that the interfacial shear and mass transfer effects are strongly dependent on the thermophysical properties of the working fluids and the operating temperatures. Condensation of vapours on a vertical fin in the presence of non-condensable gas formulated and solved for a wide range of system parameters, making use of the analogy between heat and mass transfer, was investigated numerically by Sarma et al. [3]. The analysis of condensation of vapour on a fin has revealed non-isothermal conditions of the thin fin with the temperature of the liquid-vapour interface, also changing along the length of the fin.

The objective of our study is to solve the present problem by using the film method, which holds in account the influence of mass transfer on the thermal calculation, and the estimate of the fin portion which works in wet regime.

\section{Heat and mass transfer formulation}

The heat and mass transfer model was the subject of many studies (see for example, [4-6]). The film method (or Colburn-Hougen method), based on the equations of mass, momentum, and energy, is used here. In this method, the analogy between the heat and mass transfer is considered. The temperature and concentration gradients take place in film. In the region close to the interface, the molecular properties play an important role. The flow inside the film is supposed to be laminar. The total heat flux density is the sum of the heat flux density and the latent heat flux density:

$$
\varphi_{\text {tot }}=h_{\mathrm{e}}^{*}\left(\theta_{\mathrm{m}, \mathrm{e}}-\theta_{\mathrm{I}}\right)+\frac{K_{\mathrm{m}}}{\Delta P_{\mathrm{ml}_{\mathrm{a}}}} L^{\prime}\left(P_{\mathrm{v}, \mathrm{m}}-P_{\mathrm{v}, \mathrm{I}}\right)
$$

In the case of finned tubes, it is necessary to take account of temperature drops through the condensation film and within the fin; hence, the total heat flux density becomes

$$
\varphi_{\mathrm{tot}}=\eta_{\mathrm{g}} h_{\mathrm{e}, \mathrm{tot}}^{*}\left(\theta_{\mathrm{m}, \mathrm{e}}-\theta_{\mathrm{I}}\right)
$$

where $h_{\mathrm{e}, \text { tot }}^{*}$ is the apparent heat transfer coefficient with condensation, which is higher than the heat transfer coefficient of the gas phase in wet regime, $h_{\mathrm{e}, \text { tot }}^{*} \gg h_{\mathrm{e}}^{*}$ (in dry regime, $h_{\mathrm{e}, \text { tot }}^{*}=h_{\mathrm{e}}^{*}=h_{\mathrm{e}}$ ). 
The total exchange surface efficiency $\eta_{\mathrm{g}}$ is equal to 1 for the smooth tubes, and $\eta_{\mathrm{g}} \leq 1$ for the finned tubes. The various heat transfer coefficients necessary to the evaluation of the heat transfer in the heat exchanger are calculated according to Gnielinski [7], for the inner heat transfer coefficient of tubes $h_{i}$, and according to Gnielinski [8] for the heat transfer coefficient outside the tubes $h_{\mathrm{e}}$ in the case of smooth tubes. In the case of finned tubes, the heat transfer coefficient outside the tube $h_{\mathrm{e}}$ is calculated according to the tubes bundle arrangement: for the staggered and aligned bundle, the expressions of $h_{\mathrm{e}}$ in the reference (PFR [9]) are used.

Several analytical and experimental studies on the shear stress effect due to the vapour over an insulated horizontal tube were made. Shekriladze and Gomelauri [11] extended the Nusselt analysis, by introducing a boundary condition of the shear stress on the free face of condensation film, and arrived to obtain an approximate solution. Their relation was modified, thereafter, by Butterworth [12], in order to obtain an interpolation satisfying the two boundary cases: condensation controlled by the gravity and shear stress. The combined heat transfer coefficient is calculated from the following equations:

$$
\begin{aligned}
& K_{\mathrm{c}}=\left[\frac{1}{h_{\mathrm{i}}} \frac{S_{\mathrm{e}}}{S_{\mathrm{i}}}+\frac{S_{\mathrm{e}}}{2 \pi \lambda_{t} l} \ln \frac{d_{\mathrm{e}}}{d_{\mathrm{i}}}+\frac{1}{\eta_{\mathrm{g}} h_{\mathrm{c}}}\right]^{-1} \\
& \varphi_{\text {tot }}=K_{\mathrm{c}}\left(\theta_{\mathrm{I}}-\theta_{\mathrm{m}, \mathrm{i}}\right)
\end{aligned}
$$

where the heat transfer coefficient of film condensation $h_{\mathrm{c}}$ for a horizontal finned tube is given by Beaty and Katz [10].

In this case, the fouling resistances are neglected. The finned surface efficiency $\eta_{\mathrm{g}}$ in dry regime is

$$
\eta_{\mathrm{g}}=1-\left(1-\eta_{\mathrm{f}}\right) \frac{S_{\mathrm{as}}}{S_{\mathrm{a}}}
$$

where the fin efficiency in wet regime $0 \leq \eta_{\mathrm{f}} \leq 1$ is given by Marto [13]:

$$
\begin{aligned}
& \eta_{\mathrm{f}}=\frac{\tanh \left(\zeta L_{\mathrm{ac}}\right)}{\zeta L_{\mathrm{ac}}} \\
& \zeta=\sqrt{2 \frac{h_{\mathrm{e}, \mathrm{tot}}^{*}}{\lambda_{\mathrm{f}} \delta_{\mathrm{f}}}}
\end{aligned}
$$

The flow configuration here concerns a humid air flow (primary fluid) horizontal and perpendicular to tubes, in aligned and staggered arrangement. In our computer code, we have studied three types of

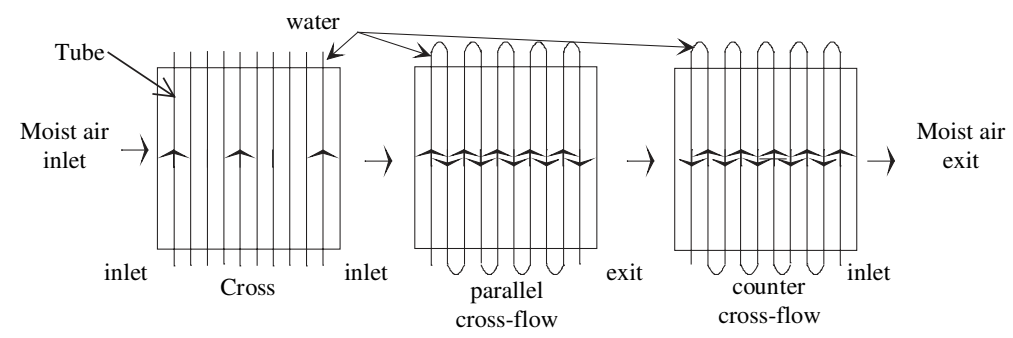

Fig. 1. Secondary fluid flow configuration. 
secondary water-fluid flows inside the tubes (Fig. 1). In order to use the variable thermophysical properties with the temperature and pressure, the heat exchanger is cut out in several meshes. The elementary heat balance equations, by using the total heat transfer coefficient notion, are used for each mesh [14].

\section{Experimental loop}

In our study, the experimental loop is destined for the test air-water heat exchangers (Fig. 2). We aim by the experimental tests to obtain the values of heat transfer rates and condensation flowrate exchanged during the condensation of the humid air on smooth or finned tubes, in order to validate our code. The general diagram of the experimental loop comprises the air and water circuit (Fig. 2).

The circuit (primary) is able to provide an air flowrate from 2000 to $10,000 \mathrm{~m}^{3} \mathrm{~h}^{-1}$ on a temperature level ranging between 100 and $450{ }^{\circ} \mathrm{C}$. It is equipped with a gas burner of $1.8 \mathrm{MW}$. It can function in open circuit or with a recycling. It is also possible by-pass a part of the hot air resulting from the burner in order to adjust the flowrate and to standardize the temperature profile at the inlet of the heat exchanger. In order to be able to vary the air moisture, the circuit is equipped with a water vapour injection, provided by the boiler $\left(10\right.$ bar, $200{ }^{\circ} \mathrm{C}$ and $\left.700 \mathrm{~kg} \mathrm{~h}^{-1}\right)$. A static mixer ensures the homogeneity of the air-vapour mixture, which is controlled by an air dew temperature measurement. The secondary circuit consists of a half-closed water loop fitted with a supplement, permitting to evacuate the thermal power. The maximum water flow circulating in the heat exchanger is about $20 \mathrm{~m}^{3}$ $\mathrm{h}^{-1}$. The inlet water temperature varies from $17.5^{\circ} \mathrm{C}$ to $24.6{ }^{\circ} \mathrm{C}$ (Fig. 2).

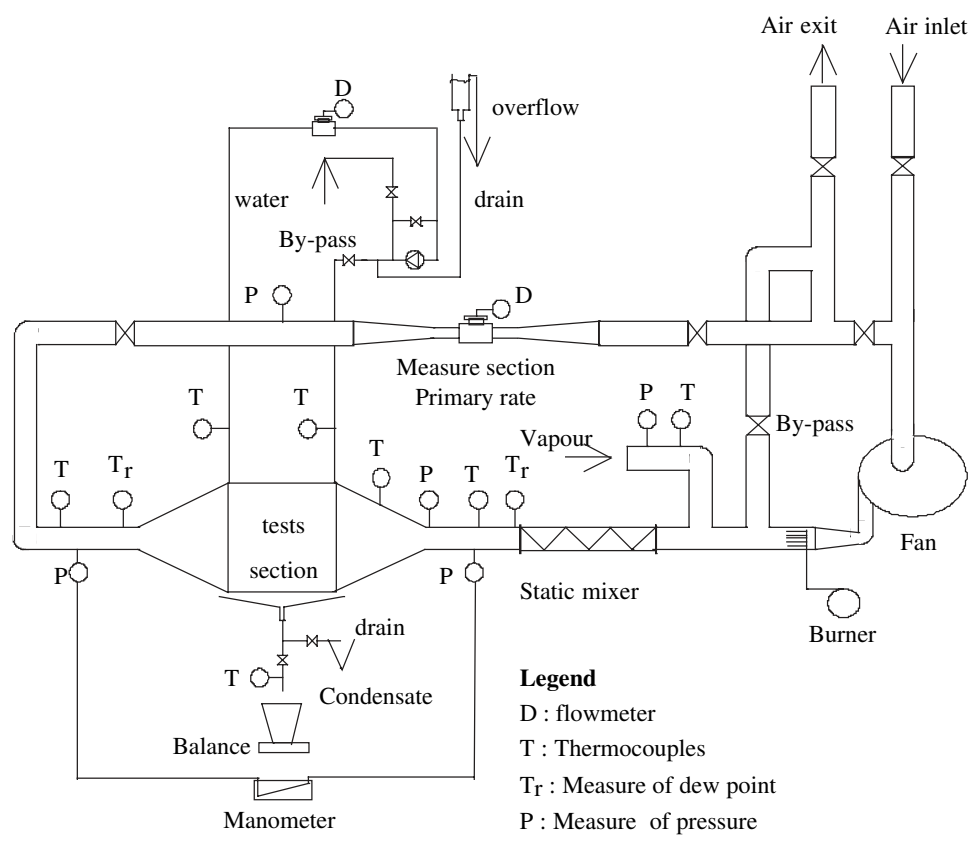

Fig. 2. General diagram of the experimental loop. Measurement circuit of dew temperature. 
Table 1

Geometrical data

\begin{tabular}{llll}
\hline Geometry no. & 1 & 2 & 3 \\
\hline Inner diameter tubes & $25.0 \mathrm{~mm}$ & $25.0 \mathrm{~mm}$ & $32.0 \mathrm{~mm}$ \\
Outer diameter tubes & $31.8 \mathrm{~mm}$ & $31.8 \mathrm{~mm}$ & $38.1 \mathrm{~mm}$ \\
Outer diameter fin & - & $62.0 \mathrm{~m}$ & $58.0 \mathrm{~mm}$ \\
Length of tube & $700 \mathrm{~mm}$ & $700 \mathrm{~mm}$ & $700 \mathrm{~mm}$ \\
Thickness of fins & - & $1.2 \mathrm{~mm}$ & $1.2 \mathrm{~mm}$ \\
Number of fins per meter & - & $160.0 / \mathrm{m}$ & $160.0 / \mathrm{m}$ \\
Longitudinal pitch & $79.0 \mathrm{~mm}$ & $79.0 \mathrm{~mm}$ & $82.0 \mathrm{~mm}$ \\
Transversal pitch & $66.4 \mathrm{~mm}$ & $91.0 \mathrm{~mm}$ & $100.0 \mathrm{~mm}$ \\
Number of tubes per row & 12 & 9 & 8 \\
Number of rows & 10 & 10 & 10 \\
Bundle & Staggered & Staggered & Aligned \\
\hline
\end{tabular}

The heat exchanger chosen in our study is constituted of a steel box and an interchangeable tube bundle. The water flow inside the tubes is cross with counter flow. The hot humid air circulates in a horizontal and perpendicular direction to the 10 rows of tubes, while the water used for the air-cooling circulates on the 10 passes inside the tubes. The technique characteristics of the geometries considered are grouped in Table 1.

\section{Results and discussion}

In dry regime, we can notice that the difference between the measured and calculated thermal power does not exceed $5 \%$. This result indicates that the values obtained from the computer code are validated in dry regime.

In wet regime, the fin portion working in a wet regime is given from the calculation of the temperature distribution over the fin. The difference between calculation and measurement is between $0 \%$ and $20 \%$ for the majority of tests (Fig. 3a-b). When the heat exchanger works in wet regime, the condensation of the water vapour is done mainly towards the exit of the heat exchanger: the water and tubes wall temperature is lower at the exit of the counter cross-flow heat exchanger. Except, the water and wall temperatures, the same remark remains valid for a parallel cross-flow heat exchanger.

(a)

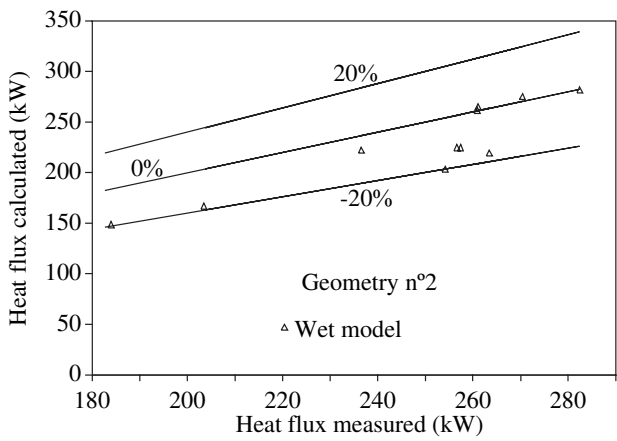

(b)

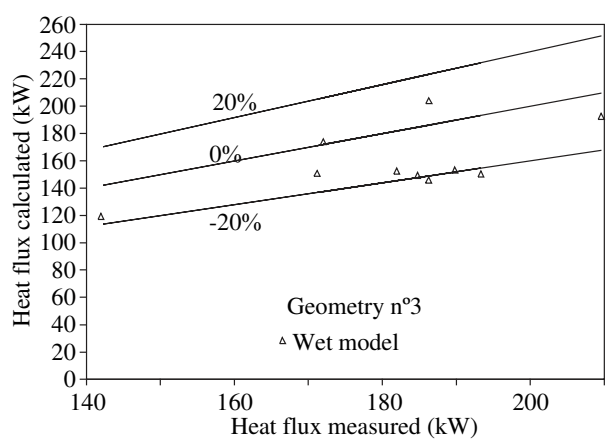

Fig. 3. Comparison between calculation and measurement in wet model. (a) Geometry no. 2, and (b) Geometry no. 3. 
(a)

(b)
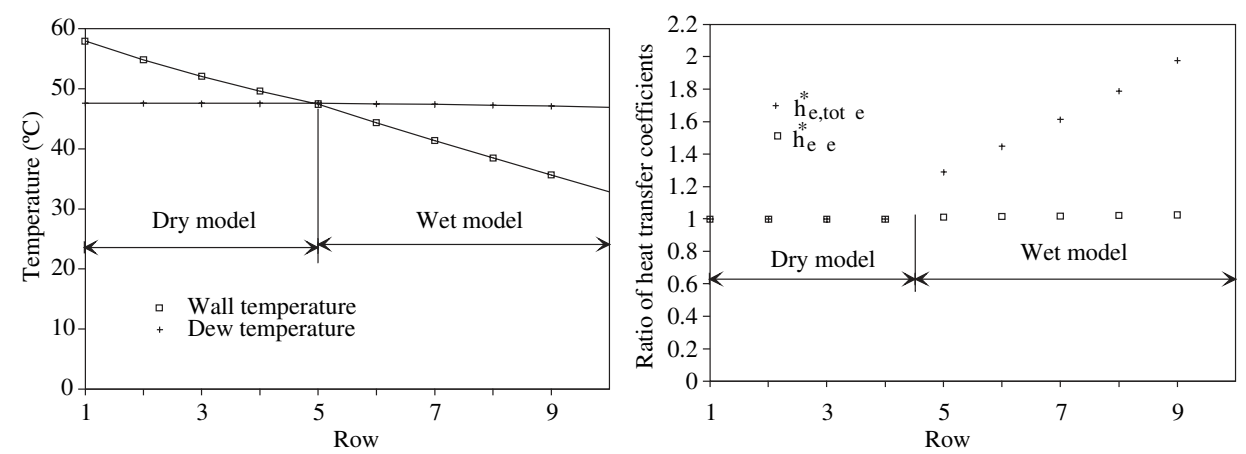

Fig. 4. (a) Dew and wall temperature via the number of row. (b) Ratio of heat transfer coefficients via the number of row.

For example, we give the dew and the outer tubes wall temperature evolution for a flow with counter-flow (Fig. 4a). For this example, we can notice that the heat exchanger works in wet regime. The apparent heat transfer coefficient with condensation $h_{\mathrm{e}, \text { tot }}^{*}$ is very large, it can exceed 10 times the value of $h_{\mathrm{e}}$. This is due to the strong apparent specific heat of the saturated humid air. For example, we give Fig. 4b, where the apparent heat transfer coefficient is the double of the heat transfer coefficient of the humid air. The effective heat transfer coefficient of the gas phase $h_{\mathrm{e}}^{*}$ to the heat transfer coefficient ratio outside the tubes $h_{\mathrm{e}}$ is about $10 \%$ (it is equal to the Ackermann's coefficient). The $h_{\mathrm{e}}^{*}$ can reach $170 \mathrm{~W} \mathrm{~m}^{-2} \mathrm{~K}^{-1}$ and $100 \mathrm{~W} \mathrm{~m}^{-2} \mathrm{~K}^{-1}$, in wet and dry regime, respectively. The total heat transfer coefficient $K$ can reach $100 \mathrm{~W} \mathrm{~m}^{-2} \mathrm{~K}^{-1}$.

The fin portion, which works in wet regime grows towards the exit of the heat exchanger. In our tests, the code estimates that the maximum fin portion working in wet regime is about $12 \%$. We can notice that for the same conditions at the inlet of the heat exchanger and the same flowrate of the secondary fluid circulating inside each tube, the cross-flow configuration is most efficient. Whereas, the counter cross-flow configuration is most powerful.

The latter can exchange 50\% more than one simple cross heat exchanger. The difference between the heat flux exchanged in a counter cross-flow and with parallel cross-flow heat exchanger is lower than $10 \%$.

\section{Conclusion}

We have developed a model permitting to simulate the heat transfers by condensation of the humid air on finned tubes bundles, by using the film method. For finned tubes, the knowledge of the fin surface, which works in wet regime is very important for the heat transfer rate calculation evacuated by the heat exchanger. In wet regime, the effective heat transfer coefficient of the gas phase and the apparent heat transfer coefficient with condensation, grow proportionally, with the condensation flowrate. The apparent heat transfer coefficient with condensation can exceed 10 times the value of the heat transfer coefficient of the gas phase.

\section{Nomenclature}

$d \quad$ Diameter of tube, $\mathrm{m}$

$h \quad$ Heat transfer coefficient, $\mathrm{W} \mathrm{m}^{2} \mathrm{~K}^{-1}$

$h^{*} \quad$ Effective heat transfer coefficient of the humid air, $\mathrm{W} \mathrm{m}{ }^{-2} \mathrm{~K}^{-1}$

$K_{\mathrm{C}} \quad$ Combined heat transfer coefficient, $\mathrm{W} \mathrm{m}{ }^{-2} \mathrm{~K}^{-1}$ 
$K_{\mathrm{m}} \quad$ Mass transfer coefficient, $\mathrm{kg} \mathrm{m}^{-2} \mathrm{~s}^{-1}$

$L^{\prime} \quad$ Latent heat, $\mathrm{J} \mathrm{kg}^{-1}$

$l \quad$ Length of tube, $\mathrm{m}$

$L_{\mathrm{ac}} \quad$ Length of the corrected fin, $\mathrm{m}$

$P_{\mathrm{v}} \quad$ Vapour pressure, $\mathrm{Pa}$

$\Delta P_{\mathrm{ml}} \quad$ Log-mean pressure difference, $\mathrm{Pa}$

$S_{\mathrm{a}} \quad$ Exchange surface of finned tubes per meter, $\mathrm{m}$

$S_{\text {as }} \quad$ Exchange surface of fins per meter, $m$

$S \quad$ Exchange surface, $\mathrm{m}^{2}$

\section{Greek Letters}

$\delta \quad$ Thickness, $\mathrm{m}$

$\varphi \quad$ Heat flux density, $\mathrm{W} \mathrm{m}^{-2}$

$\eta_{\mathrm{f}} \quad$ Fin efficiency

$\eta_{\mathrm{g}} \quad$ Total finned surface efficiency

$\lambda$ Tube thermal conductivity, $\mathrm{W} \mathrm{m}^{-1} \mathrm{~K}^{-1}$

$\theta \quad$ Temperature, ${ }^{\circ} \mathrm{C}$

$\zeta \quad$ Anisothermy coefficient

\section{Indices}

$\begin{array}{ll}\mathrm{c} & \text { Condensate } \\ \mathrm{e} & \text { Outside } \\ \mathrm{f} & \text { Fin } \\ \mathrm{I} & \text { Interface } \\ \mathrm{i} & \text { Interior } \\ \mathrm{m} & \text { Average } \\ \mathrm{tot} & \text { Total } \\ \mathrm{t} & \text { Tube }\end{array}$

\section{Acknowledgments}

This study was carried out and financed by le Groupement pour la Recherche sur les Echangeurs Thermiques (Greth-CEA/Grenoble-France), to which we address our thanks.

\section{References}

[1] H. Ay, J.Y. Jang, J. Yeh, Int. J. Heat Mass Transfer 45 (2002) 20.

[2] Y. Pan, Int. J. Heat Mass Transfer 44 (2001) 23.

[3] P.K. Sarma, M.A. Reddy, A.E. Bergles, S. Kakac, Int. J. Heat Mass Transfer 44 (2001) 17.

[4] A.P. Colburn, O.A. Hougen, Chem. Ind. Eng. 26 (1934) 11.

[5] J.G. Collier, Convective Boiling and Condensation, 2nd ed., McGraw-Hill, Maidenhead, 1981, p. 737.

[6] G. Ackermann, Ver. Deutsch. Ing.-Forschungsh. 8 (1937) 382. 
[7] V. Gnielinski, Chem. Eng. 16 (1976) 2.

[8] V. Ginielinski, Forsch. Ing.Wes. 44 (1978).

[9] P.F.R. Engineering Systems, Heat transfer and pressure drop characteristics of dry towers extended surfaces: Part II. Data analysis and correlation. P.F.R. BNWL-BFR-7-102, Marina del Rey, California, 1976.

[10] K.O. Beaty, D.L. Katz, Chem. Eng. Prog. 44 (1948) 1.

[11] I.G. Shekriladze, V.I. Gomelauri, Int. J. Heat Mass Transfer 9 (1966).

[12] D. Butterworth, in: ASME Winter Annual Meeting, 27 Nov.-2 Dec., 1977, Atlanta, Georgia, ASME Paper, 1977, 77-WA/HT-24.

[13] P.J. Marto, J. Heat Transfer 110 (1988) 2.

[14] J.L. Armand, N. Molle, Characterization of finned tubes heat exchangers: application to performance simulation, Proc. European Conf. on Finned Tube Heat Exchanger, Lyon, 1991. 